\title{
SPLENIC INJURY-ANALYSIS OF CLINICAL SIGNS AND OUTCOMES
}

\author{
Konstantin Kostov \\ Department of General, Visceral and Emergency Surgery, UMHATEM Pirogov \\ - Sofia, Bulgaria.
}

\section{SUMMARY}

Purpose: The purpose of this study is to analyze clinical findings and treatment outcomes in patients with splenic injury from blunt abdominal trauma.

Material and Methods: Data from 49 patients with splenic injury from blunt abdominal trauma was processed within a retrospective clinical analysis for the period of 1.1. 2014 to 31.12. 2015 in the General, Visceral and Emergency Surgery Section of the UMHATEM "Pirogov". Of the hospitalized women were 18 (36.73\%), men 31 (63.27\%). The age in this retrospective analysis ranged from 18 to 83 years (average 45.7 years).

Results: Splenectomy was performed in 46 patients $(93.88 \%)$ and in the remaining three- definitive haemostasis. Hospital stays varied from 6 to 17 days (average 7.4 days). Morbidity rate was $12.24 \%$ (6 patients). Mortality rate- $8.16 \%$

Conclusions: Most patients with injury of the spleen from blunt abdominal trauma present with signs of abdominal pain and tenderness. Much of them have trauma or injury to the lower left chest, indicating a possible lesion of the spleen. Timely identification, aggressive resuscitation therapy and optimal surgical intervention are the steps toward favorable results.

Keywords: splenic injury, blunt abdominal trauma, surgery, clinical signs, symptoms,

\section{INTRODUCTION}

The spleen is the most commonly injured organ in blunt abdominal trauma [1]. The injuries of the spleen can be life threatening. They may be the leading cause of preventable death in traumatic patients who are hemodynamically stable but with missed or delayed diagnosis of intra-abdominal injuries [2]. Therefore, rapid initial diagnosis of spleen injuries is crucial. Unfortunately, spleen injuries may be asymptomatic, i.e., to be present with- out abdominal pain or tenderness even in nonintoxicated patient [3-5]. For this reason, additional clinical and laboratory tests are needed to identify patients with splenic lesions.

The presence of various clinical findings in blunt abdominal trauma such as hypotension, abdominal pain or tenderness, low hemoglobin or low hematocrit and gross haematuria, lead us to the diagnosis of traumatic splenic injury. In addition, in patients with altered consciousness, levels there is a difficulty in diagnosing spleen lesions due to challenges of communication and effective clinical examination.

Both the liver and the spleen are protected from blunt injury by the lower chest wall. Therefore, the presence of rib fractures in these segments may lead to injury to the liver or spleen [6]. Two studies have suggested that injury to the chest is an independent predictor of intra-abdominal injury and patients with significant chest injury require abdominal computed tomography (CT) to delineate intraabdominal injury [7, 8].

The aim of our study is to analyze clinical findings, to determine the prevalence of significant left lower chest injury and treatment outcomes in patients with spleen injury from blunt abdominal trauma. Finally, we attempted to determine if the finding of left lower chest injury might be the single clinical indicator of splenic injury.

\section{MATERIAL AND METHODS}

Data from 49 patients with splenic injury from blunt abdominal trauma, were processed within a retrospective clinical analysis for the period of 1.1. 2014 to 31.12. 2015 in the General, Visceral and Emergency Surgery Section of the UMHATEM "Pirogov". Of the hospitalized women are $18(36.73 \%)$, men $31(63.27 \%)$. The clinical diagnosis was based on history, physical examination, laboratory results, radiography, echography 
and CT. History and physical examination included: mechanism of injury, presence of hypotension $(<90 \mathrm{mmHg})$, complaining of abdominal pain and tenderness. Laboratory data guided us to the diagnosis through low hemoglobin and hematocrit, gross hematuria and leukocytosis.

Significant left lower chest injury was considered present based on abnormal findings either on physical examination or radiologic studies. Via radiographic evaluation, significant left lower chest injury was considered present if plain chest radiograph or abdominal CT demonstrated left sided rib fractures to any of ribs seven through 12[6]. On physical examination, significant left lower chest injury was considered present if patients were diagnosed with left sided chest wall tenderness (ribs $7-12$ ) associated with pleuritic chest pain. All patients' hospital courses were reviewed to identify those patients undergoing laparotomy diagnosis at laparotomy, and therapy at that time.

Patients were considered to have significant left lower chest injury as an isolated predictor of splenic injury if they had significant left lower chest injury in the absence of all the previous defined indicators of splenic injury. All patients with significant left lower chest injury as an isolated predictor of splenic injury had all additional injuries documented.

Echography and CT show non-homogeneous parenchymal spleen and free intraperitoneal fluid.

In this study, the parameters - age, gender distribution, clinical symptoms, mode of treatment, morbidity and mortality were analyzed. The age in this retrospective analysis ranged from 18 to 83 years (average 45.7 years).

Patients under 18 years of age, as well as those transported from other hospital centers with diagnosed spleen injury, were excluded from the study.

The data from all patients admitted with splenic injury from blunt abdominal trauma were carefully systematized, analyzed and summarized. The results are summarized by tracking the morbidity up to one month after discharge.

\section{RESULTS}

The main causes of the trauma were road traffic accidents - 35 cases $(71.43 \%)$, followed by criminal and domestic accidents-6 (12.24\%), high altitude injuries-5 (10.21\%) and industrial accidents-3 $(6.12 \%)$ (Table 1).
Table 1. Main causes of the trauma

\begin{tabular}{|l|c|}
\hline Main causes of the trauma & $49(100 \%)$ \\
\hline road traffic accidents & $35(71.43 \%)$ \\
\hline criminal and domestic accidents & $6(12.24 \%)$ \\
\hline high altitude injuries & $5(10.21 \%)$ \\
\hline industrial accidents & $3(6.12 \%)$ \\
\hline
\end{tabular}

Abdominal pain in the left upper quadrant (45-91.84\%) and tenderness (34-69.39\%) were recorded from the physical examinations. There were 23 patients $(46.94 \%)$ with hypotension $(<90$ $\mathrm{mmHg}$ ) or shock. Associated injuries were confirmed in 32 patients $(65.31 \%)$, like major trauma of the musculoskeletal system (11 patients), followed by thorax (9 patients), intra-abdominal lesions ( 7 patients) and cranio-cerebral trauma (5 patients)(Table 2).

Table 2. Associated injuries

\begin{tabular}{|l|c|}
\hline Associated injuries & $32(65.31 \%)$ \\
\hline $\begin{array}{l}\text { trauma of } \\
\text { the musculoskeletal system }\end{array}$ & $11(\mathbf{2 2 . 4 5 \% )})$ \\
\hline $\begin{array}{l}\text { trauma of the thorax } \\
\text { intra-abdominal lesions }\end{array}$ & $\mathbf{9 ( 1 8 . 3 7 \% )}$ \\
\hline cranio-cerebral trauma & $7(\mathbf{1 4 . 2 9 \% )}$ \\
\hline
\end{tabular}

All enrolled patients had decreased hematological parameters (hemoglobin and hematocrit), and a large group of them leukocytosis.

Intraoperatively, splenectomy was performed in 46 patients $(93.88 \%)$ and in the remaining 3 only - definitive haemostasis. Hospital stays varied from 6 to 17 days (average 7.4 days).

Morbidity was $12.24 \%$ (6 patients). Of these, 4 were with wound infection, 1 with a postoperative hernia and 1 with subileus symptoms(Table 3 ).

Table 3. Morbidity distribution

\begin{tabular}{|l|c|}
\hline Morbidity distribution & $6(12.24 \%)$ \\
\hline wound infection & $4(8.16 \%)$ \\
\hline postoperative hernia & $1(2.04 \%)$ \\
\hline subileus & $1(2.04 \%)$ \\
\hline
\end{tabular}

Mortality was $8.16 \%$ - 4 died. Mainly due to severe associated injuries and shock and were not directly related to surgical intervention. 


\section{DISCUSSION}

The majority of patients with blunt splenic injury have signs or symptoms of splenic injury. Abdominal pain in the left upper quadrant (45 patients-91.84\%) and tenderness (34 patients-69.39\%) were recorded from the physical examinations. Very often reduced consciousness is the reason why those signs and symptoms were not recognized on time. However, a drop in haematological parameters (hemoglobin and hematocrit) is present in all injured patients.

Early diagnosis of traumatic lesions of the spleen is of utmost importance in view of timely resuscitation therapy and surgery. Delayed therapeutic behavior in few cases leads to a fatal outcome in view of the severity of this type of trauma.

Several studies suggest that the use of ultrasound (FAST), CT and DPL [7,8] is useful for a definitive assessment of the severity of splenic injury in major thoracic trauma. However, these studies do not specifically assess left-sided thoracic injury and injury of the spleen. Another study focuses on the injuries of the left lower chest [6]. The authors analyzed the association between intra-abdominal injury and rib fractures (7-12 rib) in the lower chest and concluded that precisely such patients with multiple lesions have a significant risk of intra-abdominal lesions.

According to world literature, splenic injuries in men prevail over those of women. The present study also registered a dominance of the male gender. This is due to the fact that most of the aggressive drivers responsible for road traffic accidents are men; most of the criminal and domestic accidents are linked to the male gender, as well as heavy physical labor in various industries[9, 10].

Patients with polytrauma have complicated clinical findings and impaired assessment of the injuries compared to these with isolated ones. Most of the patients with recorded associated injuries in the present study had musculoskeletal and craniocerebral trauma. Spleen is one of the most vulnerable abdominal organs in polytrauma because of its specific structure and topographic features[11, 12].

In our study, all patients with traumatic splenic lesions were treated with surgery- splenectomy or local haemostasis was performed.

\section{CONCLUSION}

Most patients with splenic injury from blunt abdominal trauma present with signs of abdominal pain and tenderness. Much of them have trauma or injury to the lower left chest, indicating the possibility of the trauma of the spleen. Timely identification, aggressive resuscitation therapy and optimal surgical intervention are the steps toward favorable results.

\section{Acknowledgement}

This study did not receive any funding. There is no commercial or propriety interest.

\section{REFERENCES:}

1. Esposito TJ, Gamelli RL. Injury to the spleen. In: Trauma. 3rd edition. Feliciano DV, Moore EE, Mattox KL. editors. Stamford: Appleton \& Lange; 1996; 525550.

2. Muckart DJ, Thomson SR. Undetected injuries: a preventable cause of increased morbidity and mortality. Am J Surg. 1991 Nov;162(5):457-60. [PubMed] [Crossref]

3. Ferrera PC, Verdile VP, Bartfield JM, Snyder HS, Salluzzo RF. Injuries distracting from intraabdominal injuries after blunt trauma. Am J Emerg Med. 1998 Mar;16(2):145-9. [PubMed] [Crossref]

4. Davis JJ, Cohn I, Nance
FC: Diagnosis and management of blunt abdominal trauma. Ann Surg 1976 Jun; 183(6):672-678. [PubMed] [Crossref]

5. Rodriquez A, DuPriest RW, Shatney $\mathrm{CH}$ : Recognition of intra-abdominal injury in blunt trauma victims. Am Surg 1982 Sep: 48(9):456-459. [PubMed]

6. Schurink GW, Bode PJ, van Luijt PA, van Vugt $A B$. The value of physical examination in the diagnosis of patients with blunt abdominal trauma: a retrospective study. Injury. 1997 May;28(4):261-5. [PubMed] [Crossref]

7. Mackersie RC, Tiwary AD, Shackford SR, Hoyt DB: Intraabdominal injury following blunt trauma. Arch Surg 1989 Jul; 124(7):809-813. [PubMed]

8. Grieshop NA, Jacobson LE, Gomez GA, Thompson CT, Solotkin KC. Selective use of computed tomography and diagnostic peritoneal lavage in blunt abdominal trauma. J Trauma. 1995 May;38(5):727-31. [PubMed] [Crossref]

9. Williamson J. Splenic injury: diagnosis and management. Br J Hosp Med (Lond). 2015 Apr;76(4):204-6, 227-9. [PubMed]

10. Nanavati P, Parker B, Winters ME. Delayed traumatic splenic injury. Am J Emerg Med. 2017 Feb;35(2):375.e3-375.e4. [PubMed] 
11. Liu S, Nahum K, Ferzli G. 12. McCarron EP. Splenic inSplenic rupture, liquefaction and juries. Clin Med (Lond). 2019 infection after blunt abdominal Jan;19(1):88. [PubMed] trauma. BMJ Case Rep. 2018 Sep 27;2018. pii: bcr-2018-226987. [PubMed] [Crossref]

Please cite this article as: Kostov K. Splenic injury-analysis of clinical signs and outcomes. J of IMAB. 2020 JanMar;26(1):3019-3022. DOI: https://doi.org/10.5272/jimab.2020261.3019

Received: 09/04/2019; Published online: 30/03/2020

Address for correspondence:

Konstantin Kostov, MD, PhD

Surgical Clinic, UMHATEM "N. I. Pirogov"

21, Totleben Blvd., 1606 Sofia, Bulgaria.

E-mail: dr.k.kostov@gmail.com 